\title{
TECNOLOGIA DE ULTRAVIOLETA PARA PRESERVAÇÃO DE ALIMENTOS
}

\author{
ANDRÉA MADALENA MACIEL GUEDES* \\ DAIANA NOVELLO* \\ GISELE M. DE PAULA MENDES** \\ MARCELO CRISTIANINI I**
}

\begin{abstract}
Este trabalho de revisão de literatura teve como objetivo levantar informações sobre a utilização da tecnologia ultravioleta (UV) na indústria de alimentos, seus efeitos e potenciais de aplicação. Foram abordados aspectos como origem, conceito e aplicações da tecnologia na indústria de equipamentos e mecanismos de funcionamento. A aplicação de radiação UV na descontaminação de produtos alimentícios ainda é pouco utilizada por seu baixo grau de penetração, mas sabe-se que pode ser facilmente aplicada a produtos alimentícios líquidos e sólidos. Os estudos revisados destacam o potencial que o processo ultravioleta oferece para a obtenção de produtos alimentícios mais frescos e com melhores características, podendo ser aplicado para produzir alimentos seguros, tendo em vista que esse tipo de radiação é letal para muitos microrganismos.
\end{abstract}

PALAVRAS-CHAVE: RADIAÇÃO ULTRAVIOLETA; PROCESSAMENTO DE ALIMENTOS; PRESERVAÇÃO DE ALIMENTOS.

* Doutorandas em Tecnologia de Alimentos, Universidade Estadual de Campinas (UNICAMP), Campinas, SP (e-mail: andreata@fea.unicamp.br; nutridai@pop.com.br).

** Mestranda em Tecnologia de Alimentos, UNICAMP, Campinas, SP (e-mail: gisele25@fea.unicamp.br).

*** Doutor em Ciência de Alimentos, Departamento de Tecnologia de Alimentos, FEA/UNICAMP, Campinas, SP (e-mail: olecram@fea.unicamp.br). 


\section{INTRODUÇÃO}

O processamento térmico constitui-se no tratamento mais eficaz para controle microbiano em alimentos, uma vez que pode resultar na esterilização. No entanto, não é aplicável para alguns produtos. Daí, o crescente interesse no uso de outros métodos físicos para descontaminação de alimentos, seja na superfície de sólidos ou no volume de líquidos (LÓPEZ-MALO e PALOU, 2005).

Alguns processos não térmicos vêm sendo aplicados para a preservação de alimentos sem causar os efeitos adversos do uso do calor. Um desses processos é a irradiação de alimentos com luz ultravioleta de ondas curtas (UV-C), que tem sido bastante estudada por sua eficiência na inativação microbiológica em água e superfície de diversos materiais (LÓPEZ-MALO e PALOU, 2005).

Os primeiros equipamentos comerciais de ultravioleta (UV) foram produzidos para as indústrias farmacêuticas e de aquicultura em razão de não utilizarem substâncias químicas para a descontaminação. Depois, surgiu o interesse para a utilização desses equipamentos nas indústrias de alimentos e bebidas. Diversas pesquisas têm sido desenvolvidas nessas áreas com o intuito de avaliar o efeito letal (a resposta microbiológica) de UV-C e as eventuais alterações nas características sensoriais dos produtos (LÓPEZ-MALO e PALOU, 2005). Essa tendência vem acompanhando a demanda do consumidor por produtos que preservem suas características sensoriais originais, mas que recebam tratamento mínimo para garantir sua segurança microbiológica e estabilidade.

As altas doses de UV-C utilizadas na descontaminação de alimentos têm sido associadas à perda nutricional e aparência indesejável dos alimentos (GARDNER e SHAMA, 2000 apud GUERREROBELTRAN e BARBOSA-CÁNOVAS, 2004).

O tratamento com radiação UV, processo a seco e a frio, é simples e eficaz. Pode ser considerado de baixo custo, como lembrado por GUERRERO-BELTRAN e BARBOSA-CÁNOVAS (2004), quando comparado com outros métodos de esterilização. No entanto, a principal limitação dessa tecnologia envolve o baixo grau de penetração que dificulta o alcance da radiação por toda a carga microbiana existente no alimento. Por isto, é mais utilizado em esterilização de superfície como, por exemplo, em embalagens para alimentos (MARQUIS e BALDECK, 2007) e em filmes comestíveis (GENNADIOS et al., 1998). Em líquidos, recomenda-se o fluxo turbulento durante o processamento.

Este trabalho teve como objetivo apresentar uma revisão sobre a origem e as principais características do processo de descontaminação por radiação UV, bem como o mecanismo de funcionamento de equipamentos disponíveis segundo a aplicação.

\section{ORIGEM}

A radiação ultravioleta foi descoberta em 1801 pelo cientista alemão Johan Ritter, que percebeu uma forma invisível de luz além do violeta capaz de oxidar haletos de prata, chamada de luz ultravioleta no fim do século XIX (BALL, 2007). Ocupa ampla faixa de comprimento de onda na região não ionizante do espectro eletromagnético, entre os raios X (100 nm) e a luz visível (400 nm) (BINTSIS et al., 2000), cujas subdivisões constam da Tabela 1.

TABELA 1 - CARACTERÍSTICAS DA LUZ ULTRAVIOLETA

\begin{tabular}{cccc}
\hline Tipo & $\begin{array}{c}\text { Comprimento de } \\
\text { onda }\end{array}$ & $\begin{array}{c}\text { Variação do comprimento } \\
\text { de onda }\end{array}$ & Características \\
\hline UV-A & Longo & $320-400 \mathrm{~nm}$ & Alterações na pele humana \\
(bronzeamento) \\
UV-B & Médio & $280-320 \mathrm{~nm}$ & Queimadura da pele (câncer) \\
UV-C & Curto & $200-280 \mathrm{~nm}$ & Faixa germicida (microrganismos) \\
UV-V & & $100-200 \mathrm{~nm}$ & Região de UV de vácuo \\
\hline
\end{tabular}

Fonte: GUERRERO-BELTRAN e BARBOSA-CÁNOVAS (2004). 
Alguns cientistas também utilizam as expressões UV próximo (280-200 nm), UV distante ou de vácuo (200-10 nm) e UV extremo (31-1 nm) (BALL, 2007). Radiações abaixo de $240 \mathrm{~nm}$ formam ozônio a partir do oxigênio do ar, que é tóxico e altamente reativo.

O efeito germicida da radiação ultravioleta foi detectado pela primeira vez em 1878, mas as primeiras unidades de processamento foram construídas em 1955 na Suíça e na Áustria (AGUIAR et al., 2002).

A radiação ultravioleta exerce efeitos biológicos e bioquímicos, com diversas aplicações no processamento de alimentos. Sua primeira aplicação ocorreu no tratamento de água e se estendeu para sucos, pois avanços em estudos permitiram sua aprovação pelo Food and Drug Administration (FDA).

Durante a década de 1930, a irradiação por UV foi usada em leite para aumentar o teor de vitamina D. Em 1935, aproximadamente 35 milhões de americanos consumiam leite irradiado. Mais da metade da produção de leite evaporado (um milhão de toneladas de leite fluido) era irradiada. Em 1996, passou-se a utilizar mais a radiação de raios $\gamma$ (SATIN, 1996). Diversos estudos têm sido feitos sobre a redução de patógenos em leite de cabra não pasteurizado utilizado para a produção de queijo (MATAK, 2004; MATAK et al., 2005).

A tecnologia de irradiação por UV é aplicada, desde 1930 nos Estados Unidos, em superfícies e no ar, em ambientes estéreis como hospitais. Depois foi adaptada para a esterilização de embalagens no sistema Ultra High Temperature (UHT), tais como tampas de garrafas de polietileno de alta densidade e cartões para produtos líquidos, embalagens de iogurte, copos plásticos e tampas de alumínio, além de superfícies de frutas e hortaliças para aumentar a resistência dos tecidos a microrganismos deterioradores (BINTSIS et al., 2000).

A radiação UV, originada do Sol, tem sido fator importante para controle do crescimento da maioria dos microrganismos, exceto para bactérias fotossintéticas.

Estudos têm tentado elucidar os papéis benéficos da radiação UV e sua viabilidade em outras aplicações, além das já existentes (RYSSTAD e KOLSTAD, 2006; GÜNTER et al., 2007; SAKAl, 2007).

\section{CONCEITO}

Os efeitos biológicos da radiação UV derivam da excitação e não da ionização de moléculas (KAREL e LUND, 2003). A energia, meio germicida, não fornece radioatividade residual como a radiação ionizante (radiação gama).

No comprimento de onda germicida, a radiação UV-C é suficiente para causar deslocamento físico de elétrons e quebra de ligações no ácido desoxirribonucleico (DNA) dos microrganismos. Isso altera seu metabolismo e reprodução, ou seja, a injúria aos sistemas de reprodução das células as levam à morte (GUERRERO-BELTRÁN e BARBOSA-CÁNOVAS, 2004).

A radiação UV apresenta baixo comprimento de onda e intensa energia, assim como a energia de uma ligação química e a de um fóton, capaz de provocar sérias consequências fisiológicas como, por exemplo, a inativação do DNA, que é vital às funções metabólicas e reprodutivas de microrganismos (BALL, 2007). A radiação germicida pode produzir conjuntivite e eritema no homem, por isto deve-se tomar precauções para não ultrapassar o limite máximo de exposição ao UV-C (PHILIPS, 2004).

Bactérias suspensas no ar são mais sensíveis à radiação UV-C do que as suspensas em líquidos, devido à capacidade de penetração diferente da luz UV-C através de diferentes meios físicos. A luz incidente é atenuada enquanto atravessa o meio, em maior ou menor grau, de acordo com o coeficiente de absorção, mesmo em água que apresenta a maior taxa de transmissividade. A maior intensidade de cor ou turbidez do líquido eleva o coeficiente de absorção, o que implica em menor penetração de luz através do sistema. A Tabela 2 apresenta os coeficientes de absorção $(\alpha)$ de alguns alimentos líquidos. 
TABELA 2 - COEFICIENTES DE ABSORÇÃO ( $\alpha$ ) DE ALIMENTOS LÍQUIDOS (253,7 nm)

\begin{tabular}{cc}
\hline Líquido & $\alpha\left(\mathrm{cm}^{-1}\right)$ \\
\hline Água potável & $0,02-0,10$ \\
Molhos claros & $2-5$ \\
Vinho branco & 10 \\
Cerveja & $10-20$ \\
Molhos escuros & $20-50$ \\
Vinho tinto & 30 \\
Leite & 300 \\
\hline
\end{tabular}

Fonte: SHAMA (1999) apud LÓPEZ-MALO e PALOU (2005).

A radiação UV-C não gera subprodutos indesejáveis, ou resíduos químicos (CHANG et al., 1985 apud GUERRERO-BELTRÁN e BARBOSA-CÁNOVAS, 2004) e não causa alterações sensoriais. Devido ao baixo grau de penetração é mais eficiente sobre superfícies ou materiais transparentes, como ar, água e polietileno. A aplicação deve ser feita diretamente sobre o alvo (BACHMANN, 1975 apud GUERRERO-BELTRÁN e BARBOSA-CÁNOVAS, 2004).

Os comprimentos de onda mais eficazes na região ultravioleta para a inativação de microrganismos situam-se a aproximadamente $260 \mathrm{~nm}$, que corresponde à região específica em que são absorvidos pelo DNA celular (SASTRY et al., 2000 apud LÓPEZ-MALO e PALOU, 2005). Como a composição de DNA varia entre espécies, considera-se que o pico de absorção de UV-C encontra-se na faixa de 260 a 265 nm (bastante próximo ao principal comprimento de onda de emissão de lâmpadas de mercúrio de baixa pressão e da maior eficiência dessa fonte de luz na inativação de microrganismos). Comprimentos de onda maiores que $300 \mathrm{~nm}$ anulam o efeito letal aos microrganismos.

Expressa-se a intensidade da radiação UV como irradiância ou intensidade de fluxo $\left(\mathrm{W} / \mathrm{m}^{2}\right)$. A dose é uma função da intensidade e do tempo de exposição, sendo expressa como exposição radiante $\left(\mathrm{J} / \mathrm{m}^{2}\right)$ (GIESE, 1964 apud BINTSIS et al., 2000).

\section{FONTES DE UV-C}

\subsection{RADIAÇÃO SOLAR}

O sol emite radiação em ampla faixa de comprimento de onda, mas a intensidade relativa dessa radiação depende da atenuação a que foi submetida pela atmosfera, por absorção e por dispersão. UV-C é completamente absorvida nas atmosferas superior e média pelo ozônio e oxigênio molecular (BINTSIS et al., 2000). É importante para o controle do crescimento da maioria dos microrganismos, exceto para bactérias fotossintéticas.

\subsection{FONTES ARTIFICIAIS}

Lâmpadas UV de ondas curtas, lâmpadas de mercúrio projetadas para produzir energia na região germicida ( $254 \mathrm{~nm}$ ), são eletricamente idênticas às lâmpadas fluorescentes, exceto pela ausência de cobertura de fósforo. As lâmpadas podem ser construídas de vidro ou quartzo, as quais permitem a transmissão de UV-C.

A fonte mais comum para produção de luz na região germicida é a lâmpada de vapor de mercúrio de baixa pressão. São cobertas por material que permite a transmissão de radiação UV-C adequada para produzir energia na região germicida (aproximadamente $254 \mathrm{~nm}$ ). As lâmpadas de quartzo oferecem maior transmitância, no entanto, seu elevado custo faz com que sejam substituídas pelas de vidro (com níveis aceitáveis de transmitância). A radiação atravessa o tubo de quartzo ou vidro e atinge os microrganismos que estão localizados no ar ou no líquido em volta da lâmpada (LÓPEZMALO e PALOU, 2005). 
Em temperatura ambiente, aproximadamente $73 \%$ da potência gerada pela lâmpada de baixa pressão produz radiação UV de 254 nm, 19\% de 185 nm e 8\% são produzidas como uma série de 313, 365, 405, 436 e $546 \mathrm{~nm}$ (LUCAS, 2003).

O bulbo, feito do quartzo tipo 219, exclui a radiação de comprimento de onda inferior a $220 \mathrm{~nm}$. Quando opera à temperatura de $40^{\circ} \mathrm{C}$, essa lâmpada emite $92 \%$ de sua radiação em $254 \mathrm{~nm}$. As lâmpadas convencionais de UV operam usando corrente alternada e produzem no máximo $25 \mathrm{~W} / \mathrm{m}$ (LUCAS, 2003).

O campo elétrico também pode ser gerado por microondas. Nesse sistema, as lâmpadas não aquecem com o tempo e há a possibilidade de se produzir ozônio e UV para se obter efeito sinérgico. Lâmpadas de quartzo 214 emitem radiação em 185 nm e 254 nm, já as 219 somente emitem radiação em $254 \mathrm{~nm}$. O campo elétrico gerado por microondas é transverso, fazendo com que a intensidade da luz UV emitida alcance ordem de magnitude maior (LUCAS, 2003).

As lâmpadas UV de baixa pressão são consideradas nos estudos de cinética de descontaminação por UV (Tabela 3).

\section{TABELA 3 - CARACTERÍSTICAS DAS LÂMPADAS UV CONVENCIONAIS}

\begin{tabular}{ccccc}
\hline $\begin{array}{c}\text { Comprimento da } \\
\text { lâmpada e arco (mm) }\end{array}$ & $\begin{array}{c}\text { Potência da } \\
\text { lâmpada (W) }\end{array}$ & $\begin{array}{c}\text { Corrente } \\
(\mathrm{A})\end{array}$ & $\begin{array}{c}\text { Potência UV } \\
(\mathrm{W})\end{array}$ & $\begin{array}{c}\text { Irradiância UV } \\
\mu \mathrm{W} / \mathrm{cm}^{2}\end{array}$ \\
\hline 212,131 & 10 & 425 & 2,9 & 24 \\
287,206 & 14 & 425 & 3,9 & 35 \\
436,356 & 23 & 425 & 7,0 & 69 \\
793,711 & 37 & 425 & 12,8 & 131 \\
\hline
\end{tabular}

Fonte: LUCAS (2003).

A eficiência das lâmpadas UV de baixa pressão está diretamente relacionada à pressão de mercúrio (saturado), que depende da menor temperatura detectada na lâmpada (PHILIPS, 2004). Essas lâmpadas têm maior utilidade na descontaminação de superfícies e podem ser instaladas no teto e no chão para descontaminação do ar, em dutos de ar, próximos à superfície. Para ser imersa em líquido, a lâmpada UV deve ser encamisada por material de quartzo ou outro material transparente ao UV-C.

O movimento do ar tem forte impacto sobre a temperatura da parede do tubo. Os efeitos de resfriamento das correntes de ar e baixa temperatura ambiente podem ser compensados pela sobrepotência das lâmpadas (PHILIPS, 2004).

A vida útil das lâmpadas de mercúrio de baixa pressão depende da geometria do eletrodo, da corrente aplicada, do preenchimento de gás nobre, da frequência de liga/desliga, da temperatura ambiente e dos circuitos elétricos.

Para descontaminação de água são usadas tanto as de baixa quanto de média pressão (policromáticas). A escolha não depende só da eficácia do UV, mas de fatores como limitações de espaço (PHILIPS, 2004). Exemplo de aplicação dos tipos de lâmpadas está na redução da atividade fotossintética de cianobactérias de algas (HIROSHI et al., 2007). Na determinação da dose, as contribuições de cada radiação de diferentes comprimentos de onda devem ser consideradas. Em descontaminação de água para impedir a formação de subprodutos indesejáveis são usados materiais que absorvem a radiação abaixo de $240 \mathrm{~nm}$ (AGUIAR et al., 2002).

\section{MECANISMOS DE FUNCIONAMENTO}

Aplica-se diferença de potencial (d.d.p.) através da lâmpada, gerando campo elétrico no interior da lâmpada que ioniza o vapor de mercúrio para produzir a emissão de luz UV (LUCAS, 2003). 
A luz UV, gerada pela lâmpada contida num tubo de quartzo, atravessa o tubo e a radiação atinge os microrganismos que estão no ar ou líquido em torno da lâmpada.

A radiação produzida pela lâmpada UV-C incide durante certo tempo no material, reduzindo a carga microbiana em alimentos líquidos (como sucos e cidra), inativando enzimas de frutas e vegetais minimamente processados, e esterilizando superfície de equipamentos de processamento e embalagens (GONZALEZ-AGUILAR et al., 2004).

Deve-se levar em consideração o fato de que esporos de microrganismos apresentam elevada resistência ao UV, e que dose subletal pode favorecer seu crescimento em vez de inibi-lo.

Uma das maiores desvantagens da radiação UV-C envolve seu baixo poder de penetração. Os microrganismos a serem inativados devem ser expostos diretamente à radiação, ou seja, não devem estar protegidos por sólidos (partículas de pó). Por outro lado, essa baixa penetração de UV-C em sólidos também o torna adequado para a descontaminação de superfícies como materiais de embalagens, frascos, garrafas, tampas e invólucros (LÓPEZ-MALO e PALOU, 2005).

Usa-se UV-C em operações de envase asséptico e para tratar superfícies de alimentos como, por exemplo, no controle do crescimento de Bacillus stearothermoplilus em camadas finas de açúcar, pescado, casca de ovo, carne porcionada, carcaças de aves, chocolate e panetone (GUERREROBELTRÁN e BARBOSA-CÁNOVAS, 2004).

A taxa de redução microbiana com a luz UV-C depende da aplicação de baixa intensidade por longo tempo ou alta intensidade por tempo curto. Devido à ampla variedade de microrganismos, e até de linhagens, os níveis da dose da descontaminação podem variar de acordo com o efeito final desejado para cada produto.

A Tabela 4 apresenta alguns exemplos de doses utilizadas para a inativação de microrganismos.

\section{TABELA 4 - DOSES ALTAS E BAIXAS UTILIZADAS PARA INATIVAÇÃO DE MICRORGANISMOS}

\begin{tabular}{|c|c|c|c|c|}
\hline Organismo & Microrganismo & Dose baixa $\left(\mathrm{J} / \mathrm{m}^{-2}\right)$ & Microrganismo & Dose alta $\left(\mathrm{J} / \mathrm{m}^{-2}\right)$ \\
\hline Alga & Chlorella vulgaris & 220 & Alga azul verde & 4200 \\
\hline $\begin{array}{c}\text { Bactéria } \\
\text { (vegetativa) }\end{array}$ & $\begin{array}{c}\text { Bacillus } \\
\text { megatherium }\end{array}$ & 25 & Sarcina lútea & 264 \\
\hline $\begin{array}{l}\text { Bactéria } \\
\text { (esporo) }\end{array}$ & Bacillus subtillis & 220 & Bacillus anthracis & 462 \\
\hline Bolores & Oospora lactis & 110 & Aspergillus niger & 3300 \\
\hline Leveduras & $\begin{array}{l}\text { Levedo de } \\
\text { cerveja }\end{array}$ & 66 & Saccharomyces sp. & 176 \\
\hline
\end{tabular}

Fonte: Adaptado de GUERRERO-BELTRÁN e BARBOSA-CÁNOVAS (2004).

Os melhores resultados no controle microbiano por UV-C estão na descontaminação de água por se tratar de meio bastante adequado para a irradiação por UV. No entanto, parte da energia se perde enquanto a luz UV atravessa a água. Além de reduzir em 99,999\% a carga microbiana em água em apenas 1 minuto, esse tratamento não ocasiona alterações de cor, sabor, odor ou pH. Aágua entra na câmara, flui dentro do espaço anular entre o tubo de quartzo e a parede externa, sendo exposta à radiação UV-C para se tornar potável e própria para consumo (GUERRERO-BELTRÁN e BARBOSACÁNOVAS, 2004).

Para descontaminação de sucos de frutas e vegetais deve-se aplicar radiação a pelo menos $400 \mathrm{~J} / \mathrm{m}^{2}$ por todo o produto. Alguns fatores críticos para essa aplicação são características de absorção, configuração geométrica do reator, potência de radiação, comprimento de onda e arranjos físicos da lâmpada, perfil de fluxo do produto e direção da radiação. O efeito produzido sofre influência da dose UV aplicada, da distância da lâmpada e da fluidodinâmica, entre outros.

A potência aplicada (dose), por sua vez, depende do número de recirculações (no caso de 
líquidos), tendo efeito cumulativo. Como exemplo, tem-se a redução de Listeria em leite de cabra (MATAK et al., 2005; REINEMANN et al., 2006). A variação da intensidade deve ser monitorada durante o tratamento (TRAN e FARD, 2004). O tempo de exposição ou tempo de residência deve ser suficiente para se atingir a redução desejada.

O FDA recomenda o fluxo turbulento para favorecer a mistura de suco ou outro fluido tratado. É importante que, no regime turbulento ou no laminar, atinja-se o tempo de residência mínimo exigido para a descontaminação (US FDA, 2000).

Entre os fatores que interferem na eficiência do tratamento com UV estão: a) presença de outras microfloras (WRIGHT et al., 2000); b) sólidos solúveis e insolúveis, pH (KOUTCHMA et al., 2004); c) fase de crescimento do microrganismo; d) temperatura da lâmpada de baixa pressão (quando menor que $25^{\circ} \mathrm{C}$, mais rápida será a formação de dímeros de timina e menor será a dose UV necessária) (SEVERIN et al., 1983 apud TRAN e FARID, 2004).

Não foram estabelecidos valores de doses mínimas a serem adotados na descontaminação com radiação UV para água. Essa definição está vinculada a diversas características particulares de cada sistema, dentre as quais se destacam: características físico-químicas da água, nível de contaminação, impacto sobre os microrganismos das etapas de tratamento anteriores ao UV, histórico epidemiológico, e grau de risco a ser assumido (AGUIAR et al., 2002). Ainda assim, há uma série de regulamentos que recomendam doses mínimas a serem adotadas nos processos de descontaminação (Tabela 5).

TABELA 5 - DOSES MÍNIMAS RECOMENDADAS PARA DESCONTAMINAÇÃO

\begin{tabular}{lcc}
\hline $\begin{array}{c}\text { Organismos } \\
\text { reguladores }\end{array}$ & $\begin{array}{c}\text { Dose recomendada } \\
\left.(\mu \mathrm{W} \mathrm{s} \mathrm{cm})^{-2}\right)\end{array}$ & Observações \\
\hline Entidades/países $_{\text {DHEW }}{ }^{1}$ & 16 & $\begin{array}{c}\text { Padrão para descontaminação em barcos } \\
\text { Classe A - descontaminação de vírus e } \\
\text { bactérias }\end{array}$ \\
ANSINSF $^{2}$ & 38 & $\begin{array}{c}\text { Classe B - descontaminação } \\
\text { complementar }\end{array}$ \\
USEPA $^{3}$ & 16 & Remoção de 2 log de vírus da hepatite A \\
Áustria & 21 & \\
França & 30 & \\
Noruega & 25 & \\
\hline
\end{tabular}

${ }^{1}$ Department of Health, Education and Welfare, USA. ${ }^{2}$ American National Standards Institute, USA. ${ }^{3}$ United States Environmental Protection Agency, USA.

Fonte: Adaptado de AGUIAR et al. (2002).

Para sucos, o FDA exige a garantia de Dose Equivalente de Redução (Reduction Equivalent Dose - RED) mínima de $400 \mathrm{~J} / \mathrm{m}^{2}$ de radiação com o comprimento de onda de 253,7 nm (US FDA, 2000). Caso contrário, pode ocorrer o fenômeno da fotorreativação, que torna os microrganismos mais resistentes ao UV-C do que os não reativados (SASTRY et al., 2000 apud GUERRERO-BELTRÁN e BARBOSA-CÁNOVAS, 2004).

Para se determinar a dose de radiação necessária para descontaminação utiliza-se o método biodosimétrico, em que o biossensor (por exemplo, esporo de Bacillus subtilis) é calibrado em relação à sua suscetibilidade ao UV em 253,7 nm. Os esporos são adicionados ao meio (ex.: água), expostos à radiação UV-C e sua concentração medida antes e depois da exposição (CABAJ e SOMMER, 2000). Esse foi considerado o único método capaz de medir a fluência média (produto da intensidade pelo tempo de exposição) na planta em todas as condições de operação. Até mesmo pequenos efeitos como a fluência da radiação refletida pelas paredes internas da planta de descontaminação (SOMMER, CABAJ e HAIDER, 1996). 


\subsection{SISTEMAS UV EM LÍQUIDOS}

O sistema UV para tratamento de líquidos pode ser simples, apenas um reator, com uma ou várias lâmpadas, ou vários reatores em série. O sistema mais simples de UV-C para tratamento de líquidos consiste em tubos concêntricos com uma lâmpada UV-C, tanques para líquidos, tubos plásticos ou sanitários, sistema de refrigeração e bombas.

Dentro do sistema concêntrico localiza-se uma lâmpada UV encamisada por material de quartzo ou outro material transparente ao UV-C, como num sistema de trocador de calor. A lâmpada fornece a dose necessária para descontaminação. Tubulações conectadas nas extremidades do reator permitem a recirculação ou o tratamento contínuo do líquido através do espaço anular entre a lâmpada e a parede do tubo externo até se atingir o efeito germicida necessário. O sistema de refrigeração pode ser usado para resfriar o líquido antes ou após o tratamento com UV. Regula-se a vazão pelas bombas e, por conseguinte, a dose de radiação fornecida ao líquido. Deve-se assegurar a mistura do material antes e depois do processamento (GUERRERO-BELTRÁN e BARBOSA-CÁNOVAS, 2004).

A unidade deve ser programada para fornecer a mesma energia para todo o material e o tempo de exposição deve ser ajustado para se atingir os níveis apropriados de energia (SASTRY et al., 2000 apud GUERRERO-BELTRÁN e BARBOSA-CÁNOVAS, 2004).

Entre os principais fatores críticos para a eficiência na redução de patógenos em sucos estão as propriedades de absorção do líquido e o impacto negativo de partículas. A coloração, a presença de sólidos solúveis e a composição dos líquidos alimentícios podem causar redução na transmissividade da radiação UV através do meio. Também são importantes o padrão de fluxo (fluidodinâmica) do reator, a distribuição de intensidade de luz e o projeto global do reator.

Com menos de 1,6 mm de espessura, qualquer líquido opaco pode ser considerado transparente ao UV se estiver na forma de filme (SARKIN, 1977 apud TRAN e FARID, 2004). Diz-se que a penetração da radiação UV-C em sucos é de aproximadamente $1 \mathrm{~mm}$ com absorção de $90 \%$. Filmes finos reduzem o caminho percorrido pela luz UV através do líquido, evitando problemas associados à falta de penetração.

O aumento de turbulência no reator conduz todo o material à maior proximidade da luz UV durante o tratamento (KOUTCHMA et al., 2004), promovendo a homogeneização. Recomenda-se fluxo turbulento, que permite agitação para maior exposição do suco que flui através do sistema. Nesse caso, velocidades mais altas garantem homogeneidade ao líquido, tornando mais rápida a inativação microbiana (KOUTCHMA et al., 2004).

Reatores conectados em série aumentam a eficiência de inativação de microrganismos. WRIGHT et al. (2002) aplicaram 9402-610005 $\mu \mathrm{W} / \mathrm{s} / \mathrm{cm}^{2}\left(94,61 \mathrm{~mJ} / \mathrm{cm}^{2}\right)$ utilizando 10 reatores conectados em série e obtiveram $3,8 \log \mathrm{UFC} / \mathrm{mL}$ de redução de $E$. coli em cidra.

HANES et al. (2002) utilizaram sistema de 3 câmaras com 8 tubos concêntricos, reduzindo o nível de oocistos em cidra para valores abaixo do nível de deteç̧ão com a dose de $14,32 \mathrm{~mJ} / \mathrm{cm}^{-2}$.

Em sistemas de tratamento de líquidos pode ocorrer o fenômeno chamado "fouling", que consiste num declínio progressivo na eficiência de inativação com o tempo, devido ao acúmulo de depósitos sobre a superfície de transferência. Esse tem sido considerado importante fator limitante da eficiência de reatores UV convencionais, principalmente devido à insuficiente mistura e elevada temperatura dentro dos reatores. O material absorve a luz UV e/ou impede a sua penetração no efluente tratado e reduz potencialmente a capacidade de descontaminação da unidade. O fluxo secundário com movimento em duplo espiral produzido por curvatura gradual em passagem fechada por meio de tubos helicoidais e espiralados pode ser uma opção para reduzir essa ocorrência. SINGH e GHALY (2006) observaram menor entupimento no reator em espiral em relação ao convencional no tratamento de soro de leite. Até 4 horas de operação, a eficiência continuou a mesma (100\%).

Em reatores para processamento de suco são usados tubos muito longos (de até $91 \mathrm{~m}$ ) com paredes transparentes, ou filmes muito finos para assegurar suficiente exposição ao UV. O projeto de reatores com tubos longos requer fluxo turbulento e mais de 38 litros de suco expostos a várias 
lâmpadas UV. Para filmes finos opera-se em fluxo laminar, sendo restrito para sucos com baixa viscosidade e isentos de polpa (FORNEY e PIERSON, 2004).

\subsection{SISTEMAS UV EM SUPERFÍCIE}

O sucesso da descontaminação depende largamente da regularidade do material a ser desinfetado, pois a radiação UV-C só inativa os microrganismos quando os atinge com dose suficiente. Então, a descontaminação só pode ser bem sucedida se toda a superfície for exposta à radiação UV. Os microrganismos localizados em orifícios da superfície provavelmente não são atingidos por reflexões das paredes dos orifícios, como pode ser deduzido pelas refletâncias mostradas na Tabela 6 . Superfícies irregulares retêm traços de material e a radiação UV não consegue atingir todos os cantos (SHAMA, 1999 apud GUERRERO-BELTRÁN e BARBOSA-CÁNOVAS, 2004).

Na prática, superfícies sólidas, material granular e embalagens (plástico, vidro, metal, cartão, etc.) são descontaminados por meio de irradiação intensiva e direta. A esterilidade pode ser mantida com a aplicação de UV no ar ambiente ao longo do percurso do material (PHILIPS, 2004). O sucesso dessa aplicação, portanto, depende da limpeza das superfícies que devem estar isentas de qualquer sujeira que absorveria a radiação, protegendo o microrganismo. Diversas aplicações são citadas por BINTSIS et al. (2000).

\section{TABELA 6 - REFLETÂNCIA DE VÁRIOS MATERIAIS À RADIAÇÃO UV-C}

\begin{tabular}{lc}
\hline \multicolumn{1}{c}{ Material } & Refletância, \% \\
\hline Alumínio: superfície não tratada & $40-60$ \\
$\quad$ superfície tratada & $60-89$ \\
Aço inoxidável & $25-30$ \\
Óxido de magnésio & $75-88$ \\
Carbonato de cálcio & $70-80$ \\
Linho & 17 \\
Lã branqueada & 4 \\
Algodão branqueado & 4 \\
Papel branco & 25 \\
\hline
\end{tabular}

Fonte: PHILIPS (2004).

Dentre os diversos estudos sobre possíveis aplicações da radiação UV-C estão a descontaminação de materiais de embalagens que não resistem ao tratamento térmico de alimento, substituição de fungicidas químicos e/ou tratamentos que alteram a cor e textura de frutas e hortaliças no controle pós-colheita (cujos alvos são membranas celulares, ácidos nucleicos, paredes celulares e enzimas), descontaminação da superfície de alimentos como carne, pescado, casca de ovos e produtos de panificação (BACHMAN, 1975 apud GUERRERO-BELTRÁN e BARBOSA-CÁNOVAS, 2004).

\section{CONTROLE E MEDIÇÕES}

Mede-se a irradiância (intensidade ou radiação) de UV por meio de instrumentos conhecidos como radiômetros (GUERRERO-BELTRÁN e BARBOSA-CÁNOVAS, 2004).

Pode-se detectar UV por fotodiodos de silicone, melhorando as respostas na faixa de 190-144 nm. Os detectores de 5,8 $\mathrm{mm}^{2}$ são alojados em caixas metálicas, enquanto que os de 33,6 e 100 mm² em caixas cerâmicas. Todas as caixas contêm uma janela de quartzo para melhorar a resposta espectral (LUCAS, 2003). Todos os sensores devem ser padronizados para irradiância, levando-se em consideração a radiação de seletividade espectral (240-290nm) para obter medidas 
reprodutíveis. A calibração normalmente ocorre por actinometria, sendo que a actinometria química também mede a dose. Os actinômetros medem a concentração de produtos originados de reações fotoquímicas, que está diretamente relacionada à quantidade de luz UV absorvida pelo produto tratado (GUERRERO-BELTRÁN e BARBOSA-CÁNOVAS, 2004).

A biodosimetria, técnica de monitoramento de irradiância mais consistente, baseia-se na inoculação de um microrganismo substituto e na medição da redução logarítmica após tratamento do fluido com UV-C sob condições específicas (GUERRERO-BELTRÁN e BARBOSA-CÁNOVAS, 2004).

A medida da radiação UV com medidores biológicos na maioria dos casos ocorre com microrganismos. O efeito biológico da inativação dos microrganismos expostos à radiação UV permite a construção da curva de sobrevivência, usada como curva de calibração. Como medidor de "biodose" podem ser utilizados, por exemplo, esporos de bactérias ou vírus (CABAJ e SOMMER, 2000).

\section{STATUS DA TECNOLOGIA}

A radiação ultravioleta, um dos métodos mais práticos para descontaminação usados no tratamento de água residual, pode inativar bactérias, vírus, esporos de bactérias e oocistos de protozoários (SALCEDO et al., 2007). Como vantagem apresenta baixa sensibilidade à temperatura em relação à cloração e à ozonação nas faixas de operação $\left(20-40^{\circ} \mathrm{C}\right)$.

O uso mais popular de descontaminação por radiação UV ocorre na produção de água potável, como alternativa ao uso de produtos químicos (cloro, ozônio, peróxido de hidrogênio). Nos Estados Unidos, em 2005, havia mais de 500 plantas de UV operando e na Europa mais de 2000. O FDA aprovou o uso de radiação UV-C para a eliminação de bactérias patogênicas em sucos em 1999, devido retenção de níveis adequados de vitaminas, devendo o produto ser declarado como levemente processado (US FDA, 2000).

\section{CONSIDERAÇÕES FINAIS}

A tecnologia de radiação UV constitui processo emergente e não térmico para descontaminação de alimentos. Potencialmente, o processo ultravioleta pode fornecer produtos alimentícios com melhores características e mais frescos.

A utilização de radiação UV para tratamento de líquidos ou sólidos deve ser estudada para obtenção de informações básicas relativas à descontaminação microbiana, pois são considerados a avaliação sensorial, qualidade e aspectos nutricionais e a vida-de-prateleira do produto.

\section{ABSTRACT}

\section{ULTRAVIOLET TECHNOLOGY FOR FOOD PRESERVATION}

This literature review article had as objective to gather information about ultraviolet (UV) technology utilization on the food industry, its effects and potential application. Aspects as the origin, concept and applications of the technology on the equipment industry and running mechanisms were approached. The application of UV radiation on food decontamination is still little used due its low penetration, but it is known that it can be easily applied to solid and liquid food products. The reviewed studies highlight the potential that the ultraviolet process offers for the production of fresh and food with better characteristics because this type of radiation is lethal for many microorganisms and can be safely applied to produce food.

KEY-WORDS: ULTRAVIOLET RADIATION; FOOD PROCESS; FOOD PRESERVATION.

\section{REFERÊNCIAS}

1 AGUIAR, A.M.S. et al. Avaliação do emprego da radiação ultravioleta na descontaminação de águas com turbidez e cor moderadas. Engenharia Sanitária e Ambiental, v. 7, n.1, 2, p. 38-47, 2002. 
2 BALL, D.W. The electromagnetic spectrum: a history. Spectroscopy, v. 3, n. 22, p.14-17, 2007.

3 BINTSIS, T.; LITOPOULOU-TZANETAKI, E.; ROBINSON, R. Existing and potential applications of ultraviolet light in the food industry - a critical review. Journal of the Science of Food and Agriculture, v. 80, n. 6, p. 637-645, 2000.

4 CABAJ, A.; SOMMER, R. Measurements of ultraviolet radiation with biological dosemeters. Radiation Protection Dosimetry, v. 91, n.1-3, p.139-142, 2000.

5 FORNEY, L.J.; PIERSON, J.A. Ultraviolet disinfection: improved methods of UV processing for fruit juices. Resource: Engineering \& Technology for a Sustainable World, v.11, n.1, p.7-8, 2004.

6 GENNADIOS, A. et al. Ultraviolet radiations affects physical and molecular properties of soy protein films. Journal of Food Science, v.63, n.2, p.1-4, 1998.

7 GONZALES-AGUILAR, G.; WANG, C.Y.; BUTA, G.J. UV-C irradiation reduces breakdown and chilling injury of peaches during cold storage. Journal of the Science of Food and Agriculture, v. 84, n. 5, p. 415-422, 2004.

8 GUERRERO-BELTRÁN, J.A.; BARBOSA-CÁNOVAS, G.V. Review: advantages and limitations on processing foods by UV light. Food Science and Technology International, v. 3, n.10, p.137-147, 2004.

9 GÜNTER, E.A.; KAPUSTINA, O.M.; POPEYKO, O.V.; OVODOV, S. Influence of ultraviolet-C on the compositions of cellwall polysaccharides and carbohydrase activities of Silene vulgaris callus. Carbohydrate Research, v. 342, p.182-189, 2007.

10 HANES, D.E. et al. Inactivation of Crytosporidium parvum oocysts in fresh apple cider using ultraviolet irradiation. Applied Environment Microbiology, v. 68, n. 8, p. 4168-172, 2002.

11 HIROSHI, S.; KUMIKO, O.; HIROYUKI, K.; SHINICHIRO, O. Effects of low- or medium-pressure ultraviolet lamp irradiation on Microcystis aeruginosa and Anabaena variabilis. Water Research, v. 41, p.11-18, 2007.

12 KAREL, M.; LUND, D.B. Physical principles of food preservation. New York: Marcel Dekker, 2003. Chap. 11.

13 KOUTCHMA, T. et al. Ultraviolet disinfection of juice products in laminar and turbulent flow reactors. Innovative Food Science and Emerging Technologies, v. 5, n. 2, p.179-189, 2004.

14 LÓPEZ-MALO, A.; PALOU, E. Ultraviolet light and food preservation. In: BARBOSA-CÁNOVAS, G; TAPIA, M.S.; CANO, M.P. Novel food processing technologies. New York: CRC, 2005. Chap. 18.

15 LUCAS, J. Integrating MAP with new germicidal techniques. In: AHVENAINEN, R. Novel food packaging techniques. Boca Ratón, Flórida: CRC, 2003. Chap. 15.

16 MARQUIS, R.E.E.; BALDECK, J.D. Sporicidal interactions of ultraviolet irradiation and hydrogen peroxide related to aseptic technology. Chemical Engineering and Processing, v. 46, n. 6, p. 547-553, 2007.

17 MATAK, K.E. Effects of UV irradiation on the reduction of bacterial pathogens and chemical indicators of milk. Blacksburg, 2004. $110 \mathrm{f}$ (Doctorate of Philosophy in food Science and Technology), Faculty of Virginia Polytechnic Institute and State University.

18 MATAK, K.E. et al. Efficacy of UV light for the reduction of Listeria monocytogenes in Goat's milk. Journal of Food Protection, v. 68, n.10, p. 2212-2216, 2005.

19 PERFECTION preserved by the purest of light. p.1-39, 2004. Disponivel em: www.uvdisinfection.philips.com/gI_en/ global_sites/ application/ water_purification /pdfs/uvp_application_brochure.pdf. Acesso em: 5 jun. 2007.

20 REINEMANN, D.J.; GOUWS, P.; CILLIERS, T.; HOUCK, K.; BISHOP, J.R. New methods for UV treatment of milk for improved food safety and product quality. St. Joseph, Michigan: American Society of Agricultural and Biological Engineers, 2006. (Paper n. 066088).

21 RYSSTAD, G.; KOLSTAD, J. Extended shelf life milk-advances in technology. International Journal of Dairy Technology, v.59, n.2, p.85-96, 2006.

22 SAKAI, H.; OGUMA, K.; KATAYAMA, H.; OHGAKI, S. Effects of low- or medium-pressure ultraviolet lamp irradiation on Microcystis aeruginosa and Anabaena variabilis. Water Research, v. 41, n. 1, p.11-18, 2007.

23 SALCEDO, I. et al. Photoreactivation and dark repair in UV-treated microorganisms: effect of temperature. Applied and Environmental Microbiology, v.73, n.5, p.1594-1600, 2007.

24 SATIN, M. Food irradiation: a guidebook. Lancaster, Pa.: Technomic, 1996.

25 SEVERIN, B.F.; SUIDAN, M.T.; ENGELBRECHT, R.S. Effects of temperature on ultraviolet light disinfection. Environmental Science and Technology, v.17, n.12, p.717-721, 1983. 
26 SHAMA, G. Ultraviolet light. In: ROBINSON, R.K.; BATT, C.; PATEL, P. (eds). Encyclopedia of food microbiology-3. London: Academic Press, 1999. p.2208-2214.

27 SINGH, J.P.; GHALY, A.E. Reduced fouling and enhanced microbial inactivation during online sterilizations of cheese whey using UV coil reactors in series. Bioprocess and Biosystems Engineering, v.29, p.269-281, 2006.

28 SOMMER, R.; CABAJ, A.; HAIDER, T. Microbicidal effect of reflected UV radiation in devices for water disinfection. Water Science Technology, v.34, n .7, p.173-177, 1996.

29 TRAN, M.T.T.; FARID, M. Ultraviolet treatment of orange juice. Innovative Food Science and Emerging Technologies, v.5, n.4, p.495-502, 2004.

30 US FDA. Food and Drug Administration. Code of Federal Regulations. Title 21, Part 179. Irradiation in the production, processing and handling of food. Federal Register, v.65, p.71056-71058, 2000.

31 WRIGHT, J.R. et al. Efficacy of ultraviolet light for reducing Escherichia coli O157:H7 in unpasteurized apple cider. Journal of Food Protection, v.63, n.5, p.563-567, 2000. 